\title{
Determination of Curve Speed Zones for Mountainous Freeways
}

\author{
Yongtao Liu $\mathbb{D},{ }^{1}$ Jie Qiao $\mathbb{D},{ }^{1}$ Yanting Hu, ${ }^{1}$ Tengyuan Fang, ${ }^{1}$ Ting Xu $\mathbb{D},{ }^{2}$ Yusheng Xiang $\mathbb{D},{ }^{3}$ \\ and Yi Han ${ }^{1}$ \\ ${ }^{1}$ School of Automobile, Chang'an University, Xi'an 710064, China \\ ${ }^{2}$ College of Transportation Engineering, Chang'an University, Xi'an 710064, China \\ ${ }^{3}$ Institute of Vehicle System Technology, Karlsruhe Institute of Technology, Karlsruhe 76131, Germany
}

Correspondence should be addressed to Jie Qiao; 2016022001@chd.edu.cn and Ting Xu; annabelxu@163.com

Received 25 August 2020; Accepted 30 October 2020; Published 29 November 2020

Academic Editor: Luigi Rodino

Copyright (c) 2020 Yongtao Liu et al. This is an open access article distributed under the Creative Commons Attribution License, which permits unrestricted use, distribution, and reproduction in any medium, provided the original work is properly cited.

Different vehicular speed limits may have an impact on the balance between safety and efficiency of travel on mountainous road corners associated with complex road conditions. Placing suitable speed limit warning signs does not merely effectively improve traffic safety but can also improve traffic efficiency. In this study, a global positioning system (GPS) terminal and Metrocount were used to collect vehicle speed data from more than 40 provincial-level curves in 8 provinces over the course of 1 year. Each road data collection time-period lasted approximately 8 hours. A descriptive statistics method was adopted by means of data screening and pretreatment. Additionally, both a velocity difference estimation model was established and a linear model of velocity differential estimation was constructed. Quantitative analysis was carried out on the safe speed, the driver's expected speed, and the location of the speed limit warning signs. This demonstrated a positive correlation with the initial speed. When the difference in speed was greater than $15 \mathrm{~km} / \mathrm{h}$, a safety warning sign was required to limit the design speed to $80 \mathrm{~km} / \mathrm{h}$. A safety warning sign was also required when the corner radius was less than $300 \mathrm{~m}$. The location of safety warning signs could be calculated based on the operating speed and taking driving safety and the visual range of drivers into consideration. The results can provide a theoretical reference for setting up appropriate safe speed limiting signs on road corners in mountainous areas.

\section{Introduction}

Curved road sections are a basic part of all highways. These driving environments involve sudden changes in curved road sections, making it difficult for drivers to safely reduce the speed of their vehicles. There are typically no clear speed limit signs on curved road sections with different curvature radii which lead to a higher accident rate. According to statistical reports on road traffic accidents (2018) [1], the number of accidents on the curved freeway road sections accounts for $8 \%$ of the total number of annual accidents with an associated mortality rate of $13 \%$. An important measure used to improve the safety of curved road sections is to use appropriate speed limits to control vehicle speed. The purpose of speed restriction is to balance traffic mobility, risk, driving time, and appropriate roadside levels associated with mountainous expressways. A reasonable speed limit is determined by using engineering evaluation. This combines the $85^{\text {th }}$ percentile speed of free movement with the road geometry, collision rate, land use rate, and vehicle driving information. With the development of intelligent vehicles in recent years, more and more studies have been performed on the safety of different driving scenarios. Mountainous freeways deserve more attention with respect to safety because they are a special scenario with high associated accident risk. Research on safe speeds for curved roads is of great significance in terms of reducing the accident rate associated with corners and enriching the driving test scenarios for intelligent vehicles.

Safe speeds for mountainous freeways are influenced by many factors. Huang et al. found that driving behavior is the most important determinant of the severity of traffic accidents in mountainous areas [2]. Li et al. found that 7 factors have a significant impact on the occurrence of deadly accidents on mountain freeways. These include factors such as downhill section, curved slope combination section, 
overspeed, and an absence of safe following distance [3]. Meng et al. found that speeding, driving experience, weather, and road conditions all have an important impact on the severity of mountain freeway accidents [4]. Wang et al. studied combinations of different road alignments and horizontal and vertical plane directions. It was found that the frequency of vehicle speed changes was significantly different for different combinations. The slope curvatures were also found to influence the speed associated with the combination horizontal and vertical mountain roads [5-7]. Wang Chuanlian et al. studied the influence of loading conditions and road conditions on the safe speed threshold of curved road sections. They also described the relationship between loading quality, road adhesion coefficient, and the threshold of safe vehicle speed [8]. Fitzpatrick found that a deceleration of $8 \mathrm{~km} / \mathrm{h}$ on a curved road section may be associated with a $90 \%$ greater traffic accident rate than that associated with straight road sections. It was found that a $16 \mathrm{~km} / \mathrm{h}$ deceleration on a curved road section may increase the rate of traffic accidents by more than $250 \%$. A safe speed model for curved mountain freeways was also studied based on a study of the factors influencing safe speed [9]. Zhang Hang et al. introduced the reliability theory to establish a high degree of dependability in order to increase the speed of vehicles using mountainous freeways. The vehicle turning radius and other related parameters were statistically analyzed along with their distribution rules [10]. Yue Lei et al. obtained the inverse ratio between the minimum radius of the curve, the superelevation, and the lateral attachment coefficient, which was directly proportional to the vehicle speed and was unrelated to the vehicle parameters [11]. Guo et al. put forward a modeling method for speed on curved road sections based on the continuous change in the design parameters of the upper and lower reaches of mountainous freeways. It provided a modeling idea that could produce continuous speed data [12]. Additionally, other studies have shown that a speed sign should be set up for curved road sections which indicate that there are dangerous situations ahead of drivers who are not familiar with the road conditions and that it is necessary to decelerate on sections such as sharp curves and steep slopes. It was also found that when drivers were familiar with the specific curve road conditions, the probability of their observing the speed limit signs was reduced, which affected their speed choice [13].

On this basis, a safe speed calculation model for mountainous freeways was studied based on human-vehicleroad coordination. Shao Yiming et al. established speed selection and acceleration and deceleration models which could describe the curve driving, driving, and departure curves based on a large number of road tests and crosssectional velocity observation data [14]. Zhao Shuen et al. used an analytic hierarchy process (AHP) and the weighted least squares method to combine the vehicle turning safety evaluation model with the critical speed and thus put forward a vehicle safety prediction model based on a synergy between man, vehicle, and road [15]. Sun Chuan et al. assumed that vehicle structural parameters could be exchanged between vehicles and roads. Driver characteristics could be incorporated to establish an improved model for calculating safe speeds for curved road sections while taking into consideration many other factors such as vehicle and road characteristics [16]. Chen et al. established a vehicle distribution prediction model and a speed prediction model to predict driver behavior and found that vehicle size, longitudinal gradients, and horizontal curves have a significant impact on the characteristics of driver behavior [17]. $\mathrm{Xu}$ et al. improved the road driving model by modifying driver operational behavior and the road design speed [18]. By referring to actual accident data, $\mathrm{Wu}$ Yan et al. analyzed the statistical characteristics of traffic accidents involving large vehicles on road corners in mountainous areas. They came to the conclusion that the recommended speed on a bend radius $R$ of $1000 \mathrm{~m}, 650 \mathrm{~m}, 500 \mathrm{~m}, 400 \mathrm{~m}, 300 \mathrm{~m}$, and $200 \mathrm{~m}$ was $75 \mathrm{~km} / \mathrm{h}, 65 \mathrm{~km} / \mathrm{h}, 55 \mathrm{~km} / \mathrm{h}, 45 \mathrm{~km} / \mathrm{h}$, and $35 \mathrm{~km} /$ $\mathrm{h}$, respectively [19]. $\mathrm{Xu}$ Jin et al. collected the speed, track, and acceleration parameters of two-lane highways in mountainous areas under natural driving conditions. They then analyzed the degree of correlation and sensitivity between the longitudinal acceleration, the curve parameters, and the driving speed [20]. Chen et al. established a vehicle speed prediction model based on a backpropagation (BP) neural network. The driving speed for a mountainous freeway incorporating changes in both horizontal and vertical alignment was successfully predicted [21]. Guo Yingshi et al. minimized the accident rate for an average angular change rate of approximately 0.0020 degrees per kilometer by collecting and analyzing actual road alignment indices and past accident data [22].

A study of safe speeds for mountainous freeways was simulated based on a large number of test data. Wang Heng et al. studied the regularity of variations in the side slip trajectory of a truck under different speed, radius, and adhesion coefficients. The conclusion was that the critical speed associated with side slip safety for a heavy truck on a curved road segment was $47 \sim 97 \mathrm{~km} / \mathrm{h}$ [23]. He Jiangli et al. used the Trucksim software package to perform a simulation test incorporating different road superelevations and curve radii to establish safe driving speeds for a large vehicle. It was concluded that the gap between critical safe speed and design safe speed increased with increasing radius and superelevation [24]. Yang et al. focused on unreasonable choices for the parameters of a two-dimensional following distance model at the turning points of an existing mountain freeway. It was suggested that the road width be increased to offset the placement of sight guidance safety facilities at points that do not allow sufficient visual range on left turns [25]. Wang tested the straight and curved sections of 65 groups of actual roads and found that the speed characteristics of mountainous freeways were different from those of flat, linear freeways. It was found that different guidance signs should be set according to different road alignments [26]. Zheng et al. found that an increase in road length or annual average daily traffic volume (AADT) could increase the number of crashes. Additionally, the installation of more traffic signs at reasonable intervals could reduce the frequency of these crashes [27]. Feng et al. established a safety evaluation method for the lateral and vertical alignment of mountain freeways based on a driving simulator. The results showed 
that lateral acceleration was positively correlated with the reciprocal of the radius of the curved road section [28].

In summary, experts and scholars both locally and abroad have done a lot of research on the influencing factors, calculation models, accident data, and simulation of mountainous freeways. However, no studies have yet been performed that comprehensively take driver road condition familiarity, vehicle models, safe speeds under varying road conditions, and speed warning signs into consideration in order to design a reasonable and safe speed limit standard for curved mountainous freeway sections. Therefore, the government urgently needs to formulate a reasonable speed zone standard for mountainous freeway corners. The purpose of this study is to provide uniform criteria for the appropriate speed zones of mountainous freeways.

Speed zones are typically only established on the basis of an engineering study. Advisory speed signs are typically recommended by the government for curved road sections, but these limits are not enforced. These are often set at hazardous locations, such as steep slopes, sharp curves, tight corners, and work zones. Methods for setting advisory speed limits vary from country to country.

The Manual on Uniform Traffic Control Devices (MUTCD) [29] identifies situations and locations for a variety of warning signs. It also indicates that the advisory speed may be based on any of the following criteria in the USA: (1) the $85^{\text {th }}$ percentile speed of free-flowing traffic; (2) speed corresponding to a $16^{\circ}$ ball-bank indicator reading; and (3) speed determined appropriately following an engineering study.

Oregon State University pointed out that speed zones ought to be set at locations associated with significant changes in roadside development and traffic volume. Oregon State University provided a list of recommended factors to take into consideration when setting speed zones, such as prevailing vehicle speed, roadway features, traffic characteristics and control, 3-year accident history, and human behavioral factors. The recommended minimum speed zone length is $402 \mathrm{~m}$ and the transition speed zone length is $305 \mathrm{~m}$.

Chowdhury et al. advocated a setting procedure that could be used to finish the following purpose: (1) identify when a curved road section warning sign and advisory speed were required; (2) select an advisory speed that was consistent with driver expectation [13]; and dynamic speed signs are more efficient than static speed limits and are used on curved road sections to alert drivers [30], as shown in Figure 1.

The American Association of State Highway and Transportation Officials' (AASHTO) document A Policy on Geometric Design of Highways and Streets (also known as the Green Book) states that curve speeds that do not cause driver discomfort correspond to ball-bank readings of $14^{\circ}$ for speeds of $32 \mathrm{~km} / \mathrm{h}$ or less, $12^{\circ}$ for speeds of 40 to $48 \mathrm{~km} / \mathrm{h}$, and $10^{\circ}$ for speeds of $56 \mathrm{~km} / \mathrm{h}$ or more [31].

AASHTO has provided a guide for advanced warning traffic signs. The sign placement for various deceleration conditions is shown in Table 1.
The Green Book [32] discusses the relationship between vehicular speed and side friction demands on curves with a specified radius and superelevation rate:

$$
V_{C}=\sqrt{g R\left(f_{D}+\frac{e}{100}\right)},
$$

where $V_{C}$ is curve speed in $\mathrm{ft} / \mathrm{s}, f_{D}$ is the side friction demand factor (or lateral acceleration), $e$ is superelevation rate in percent, $g$ is the gravitational acceleration $\left(32.2 \mathrm{ft} / \mathrm{s}^{2}\right)$, and $R$ is the radius of the curve in feet.

Zhou's research mentions two kinds of speed limits including legal speed limits and warning speed limits [33]. When vehicles constitute a risk to other vehicles, such as when navigating sharp curves and steep slopes, consideration should be given to setting up a "warning speed limit."

The document Specification for Layout of Highway Traffic Signs and Markings JTG D82-2009 [34] mentions that an advisory speed sign is used to remind drivers of the proposed speed limit. It is always located at ramps, curves, and exits. However, advisory speed limits cannot be used alone and should be used in conjunction with other warning signs and additional auxiliary signs, as shown in Figure 2.

In western countries, advisory speeds are typically set by using a ball-bank indicator on curves to ensure that drivers are not subjected to uncomfortable levels of lateral acceleration. However, there is very little research in this field. In foreign countries, a variety of speed limits are set according to road function, some of which may not be suitable for China.

Previous studies on traffic safety have rarely involved studying speed differences and advisory speed signs, and the factors considered are not comprehensive. On the basis of previous studies, this paper analyses the speed change law of curve sections through data collection of curve sections with different curve radius, which lays a foundation for the setting of advisory speed signs. On this basis, the influence of curve radius and approaching speed on the speed difference is analyzed, and the advisory speed limit and the setting position of advisory speed signs under different conditions are obtained. Finally, the setting methods of the advisory speed signs in different situations are obtained. The objectives of this study are as follows:

(1) Data acquisition of curve sections with different curve radius

(2) Analyze the influence factors of speed difference of curve sections

(3) To develop guidelines for identifying when speeds zones require updating

(4) To develop a model for identifying speed differences

(5) Analysis and research on the whole process of driver's recognition of advisory speed signs

(6) To recommend advisory speed signage for a given curve

(7) To develop guidelines and procedures for setting advisory speed signs 


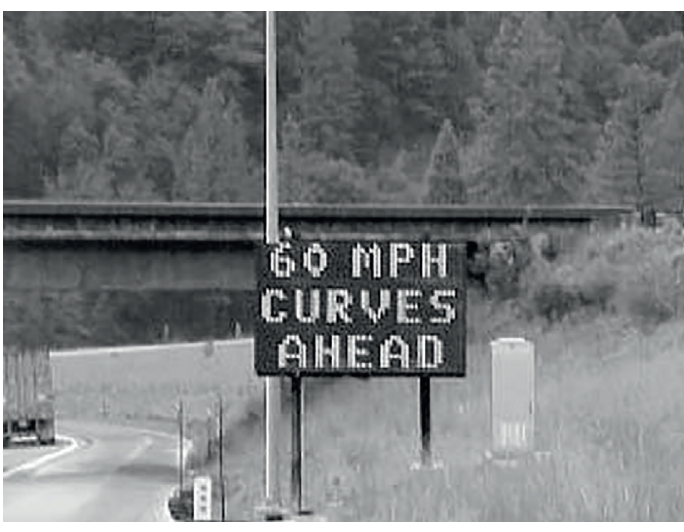

(a)

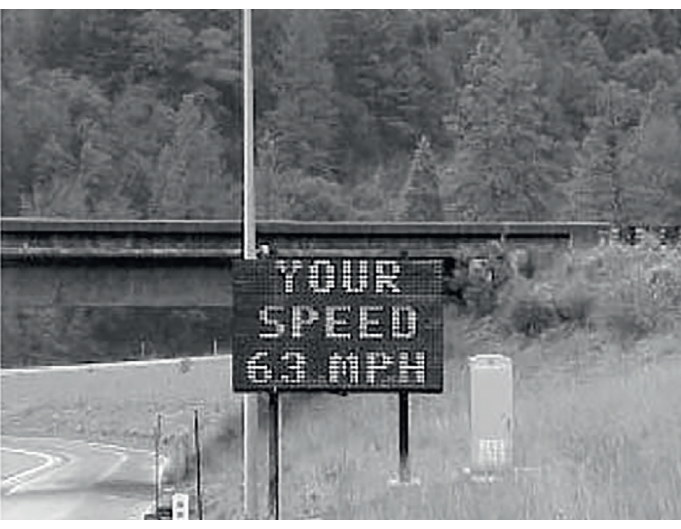

(b)

FIgURE 1: Curved road section advisory speed limit, (a) dynamic speed signs, and (b) vehicle real-time speed signs.

TABLE 1: Advanced warning sign placement distance (in feet).

\begin{tabular}{lccccc}
\hline & $\begin{array}{c}\text { Deceleration condition } \\
\text { to listed }\end{array}$ \\
$\begin{array}{l}\text { Posted speed limit }\left(85^{\text {th }} \text { percentile }\right. \\
\text { speed } \mathrm{mph})\end{array}$ & $\begin{array}{c}\text { advisory speed (mph) } \\
\text { (desired speed } \\
\text { condition) }\end{array}$ \\
& 10 & 20 & 30 & 40 & 50 \\
\hline 20 & - & - & - & - & - \\
25 & 100 & - & - & - & - \\
30 & 150 & 100 & - & - & - \\
35 & 200 & 175 & - & - & - \\
40 & 275 & 250 & 175 & - & - \\
45 & 350 & 300 & 250 & - & - \\
50 & 425 & 400 & 325 & 225 & - \\
55 & 500 & 475 & 400 & 300 & - \\
60 & 575 & 550 & 500 & 400 & 300 \\
65 & 650 & 625 & 575 & 500 & 375 \\
\hline
\end{tabular}

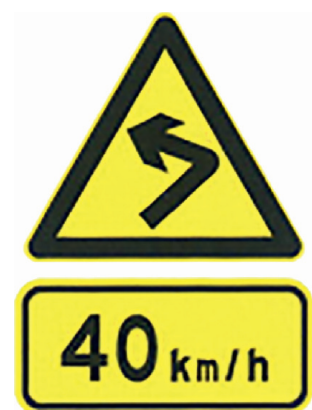

FIgURE 2: Typical warning sign presented in JTG D82-2009.

The remainder of this paper describes the traffic flow parameters collection process, establishes a speed difference estimation model, and presents a method for the determination of appropriate curve warning sign parameters. The conclusions are presented at the end of the paper.

\section{Methods}

2.1. Proposed Engineering Study. The centrifugal force will be generated when the vehicle passes through the curve section, which will cause the vehicle to sideslip or even roll over.
Hence, it is necessary to control the speed within the safe range when the vehicle enters the curve section. Advisory speed signage is used to slow vehicles from their initial approach speed to the proper curve speed. The engineering study must therefore include a statistical analysis of the speed distribution of free-flowing vehicles on the subject roadway. Different traffic flow states follow different distributions. In general, individual vehicle speeds followed a normal distribution. On the basis, the distribution characteristics of speed difference can be determined. Besides, it is recommended that the speed defined by the advisory speed signage should not be too low, or it will lead to the driver to be dissatisfied with the road service level. Hence, the need for further curve warning signs should be based on engineering considerations and driver expectations.

The setting of advisory speed signs and other curve warning signs is based on the consideration of several factors including the following:

(i) Driver approach sight distance to the beginning of the curve(s)

(ii) Unexpected geometric features within the curve(s), such as too small curve radius

(iii) Consistency in advisory speed and driver expectation

2.2. Data Collection. Due to the distinct differences in physical features and power of different types of vehicles, the document Technical Standard of Highway Engineering 2006 divides all vehicles into two groups according to axle values. Vehicles with axle distances larger than $3.8 \mathrm{~m}$ are classed as large vehicles while all others are classed as passenger cars. Mountainous freeway information was collected from Xinjiang, Yunnan, Guangdong, Shaanxi, and Sichuan provinces. Two typical spots were selected to conduct $6 \mathrm{~h}$ continuous observations at each curve. One was at the curve approach section, and the other was in the middle of the curve.

Each curve was tested using Metrocount and GPS to collect free-flow speed and volume information on the curved road sections, of which traffic flow headways were 
larger than $6 \mathrm{~s}$. Observations taking approximately $6 \mathrm{~h}$ were carried out at each site. More than 40 curves were studied, none of which contained an advisory speed sign. The basic characteristics of some curve road section are shown in Table 2.

Since roads with the same design speed may correspond to different curve radii and some road sections have similar road characteristics, Table 2 only lists some basic parameters of the surveyed roads. In the actual data collection, the sections with the curve radius ranging from $200 \mathrm{~m}$ to $700 \mathrm{~m}$ are investigated, such as $250 \mathrm{~m}, 300 \mathrm{~m}, 400 \mathrm{~m}, 500 \mathrm{~m}, 600 \mathrm{~m}$, and $700 \mathrm{~m}$, and the number of sections with each curve radius is about 5 .

The typical Metrocount layout is shown in Figure 3. Two air pressure pipes were laid on the road, and the detection principle of traffic flow was that when one air pressure pipe was continuously rolled by a secondary wheel; it can be judged to pass a motor vehicle.

2.3. Data Analysis. The radius of the horizontal curve of the expressway analyzed in this study is mainly in the range of $200 \mathrm{~m}$ to $700 \mathrm{~m}$. The operating speed on the tangential sections ranged from $80 \mathrm{~km} / \mathrm{h}$ to $105 \mathrm{~km} / \mathrm{h}$.

For a curve section with a certain curve radius, the $85^{\text {th }}$ percentile speed of the curve section can be obtained by collecting the speed values of different vehicles passing through the starting point and middle position of the curve section. The difference between the $85^{\text {th }}$ percentile speed corresponding to the two positions is the $85^{\text {th }}$ percentile speed difference of the curve section.

On this basis, the $85^{\text {th }}$ percentile speed difference of different curve sections can be classified according to the curve radius and approaching speed. Through the preliminary analysis of the main concentration range of approaching speed, it can be divided into four types: $80 \mathrm{~km} /$ h, $90 \mathrm{~km} / \mathrm{h}, 100 \mathrm{~km} / \mathrm{h}$, and $105 \mathrm{~km} / \mathrm{h}$. By calculating the $85^{\text {th }}$ percentile speed of approach speed at each curve, if the error between this value and the above reference value is within $2 \mathrm{~km} / \mathrm{h}$, the approach speed at this point can be approximately considered as this reference value. Hence, the $85^{\text {th }}$ percentile speed difference variation trend of four approaching speeds with different curve radius can be obtained. The relationship between various approach speed differences and curve radius is shown in Figure 4.

The analysis of the data presented in Figure 4 showed that the maximum speed difference was $16 \mathrm{~km} / \mathrm{h}$ and the minimum speed difference was $4 \mathrm{~km} / \mathrm{h}$. The speed difference decreased when the radius increased and it became constant when the radius was larger than $550 \mathrm{~m}$. The radius had an inverse relationship with the speed difference when it was smaller than $550 \mathrm{~m}$. Furthermore, the faster the approach speed, the larger the resultant speed difference. The results indicated that the approach speed had a significant influence on the driver curve speed choice.

2.4. Speed Difference Estimations. The speed consistency presented in the Guidelines for Safety Audit of Highway and the conclusions drawn from the Jinjintang freeway indicated that when the operating speed difference of passenger cars was larger than $15 \mathrm{~km} / \mathrm{h}$ [35], the number of traffic accidents increased sharply. Hence, it was necessary to set advisory speed signs when the curve speed was $15 \mathrm{~km} / \mathrm{h}$ lower than the approach speed. The speed difference between successive spots was used to identify when to set the advisory speed. A speed difference model was derived to describe the relationship between the speed difference and the horizontal curve radius.

Individual vehicle speeds followed a normal distribution [36]. Supposing that the operating speeds at two successive spots were $V 85_{\operatorname{car}(i)} \sim N\left(\mu_{1}, \sigma_{1}^{2}\right)$ and $V 85_{\operatorname{car}(i-1)} \sim N\left(\mu_{2}, \sigma_{2}^{2}\right)$, the difference between the speeds at the two spots can then be defined as shown in the following equation:

$$
\text { speeddiff }=V 85_{\operatorname{car}(i)}-V 85_{\operatorname{car}(i-1)},
$$

where speeddiff is the speed difference between successive points in $\mathrm{km} / \mathrm{h}, V 85_{\operatorname{car}(i)}$ is the operating speed of the passenger car at the point of approach $i$ in $\mathrm{km} / \mathrm{h}, V 85_{\operatorname{car}(i-1)}$ is the operating speed of the passenger car at the midcurve spot $i-1 \mathrm{in} \mathrm{km} / \mathrm{h}$, and $i$ is the number of the spot on the curve or at the point of approach.

Therefore, the speed difference also follows a normal distribution:

$$
\text { speeddiff } \sim N\left(\mu_{1}-\mu_{2}, \sigma_{1}^{2}+\sigma_{2}^{2}\right),
$$

where $\mu_{1}$ and $\mu_{2}$ are the sample speed mean values at spots $i$ and $i-1$ in $\mathrm{km} / \mathrm{h}$ and $\sigma_{1}$ and $\sigma_{2}$ are the sample speed standard deviation at spots $i$ and $i-1$ in $\mathrm{km} / \mathrm{h}$.

Driver speed choice on sharp horizontal curves is largely influenced by safety concerns. A linear model was derived to describe the relationship between vehicle speed difference and curve radius, as described in the following equation:

$$
\text { speeddiff }=a+V 85_{\operatorname{car}(i)}-\frac{c}{\operatorname{Radi}},
$$

where $V 85_{\operatorname{car}(i)}$ is the passenger car operating speed at the entry point $i$ in $\mathrm{km} / \mathrm{h}$, Radi is the horizontal curve radius in $m$, and $a$ and $c$ are estimation parameters.

The statistical software SPSS was applied to perform linear regression:

$$
\text { speeddiff }=-43+0.52 \times V 85_{\operatorname{car}(i)}+\frac{1368.7}{\operatorname{Radi}}
$$

It was proposed that an advisory speed sign should be based on the average of the free-flowing speed differences between successive sites.

According to the expressway alignment criteria, the minimum design speed was chosen as $80 \mathrm{~km} / \mathrm{h}$ and the maximum as $120 \mathrm{~km} / \mathrm{h}$. The minimum design radius was $250 \mathrm{~m}$. Based on equation (5), speed differences were revised when the horizontal curve radii were smaller than $700 \mathrm{~m}$. The estimation results for passenger cars are presented in Table 3 .

According to the results presented in Table 3, if the approach speed was below $100 \mathrm{~km} / \mathrm{h}$ and the curve radius was larger than $250 \mathrm{~m}$, the speed difference would not exceed $10 \mathrm{~km} / \mathrm{h}$. If a limited radius of $250 \mathrm{~m}$ was adopted, the speed difference increased beyond $10 \mathrm{~km} / \mathrm{h}$. 
TABLE 2: The basic characteristics of the curve section.

\begin{tabular}{|c|c|c|c|c|}
\hline Road type & Design speed $(\mathrm{km} / \mathrm{h})$ & Curve radius $(\mathrm{m})$ & Maximum slope (\%) & Average slope (\%) \\
\hline Expressway & 80 & 220 & $-2.7 \%$ & $-1.6 \%$ \\
\hline Expressway & 80 & 270 & $3.1 \%$ & $2.6 \%$ \\
\hline Expressway & 80 & 325 & $3.2 \%$ & $2.8 \%$ \\
\hline Expressway & 80 & 620 & $2.1 \%$ & $1.7 \%$ \\
\hline Expressway & 80 & 680 & $3.7 \%$ & $2.9 \%$ \\
\hline Expressway & 80 & 470 & $2.5 \%$ & $1.4 \%$ \\
\hline Expressway & 80 & 570 & $-3.7 \%$ & $-1.8 \%$ \\
\hline Expressway & 80 & 375 & $1.9 \%$ & $0.8 \%$ \\
\hline Expressway & 120 & 570 & $-2.7 \%$ & $-1.9 \%$ \\
\hline Expressway & 120 & 375 & $3.2 \%$ & $2.5 \%$ \\
\hline Expressway & 120 & 470 & $3.8 \%$ & $2.8 \%$ \\
\hline Expressway & 120 & 680 & $-2.9 \%$ & $-1.8 \%$ \\
\hline Expressway & 120 & 270 & $-3.5 \%$ & $-2.6 \%$ \\
\hline Expressway & 120 & 325 & $2.9 \%$ & $1.7 \%$ \\
\hline Expressway & 120 & 620 & $3.2 \%$ & $2.1 \%$ \\
\hline Expressway & 120 & 220 & $3.3 \%$ & $2.2 \%$ \\
\hline
\end{tabular}

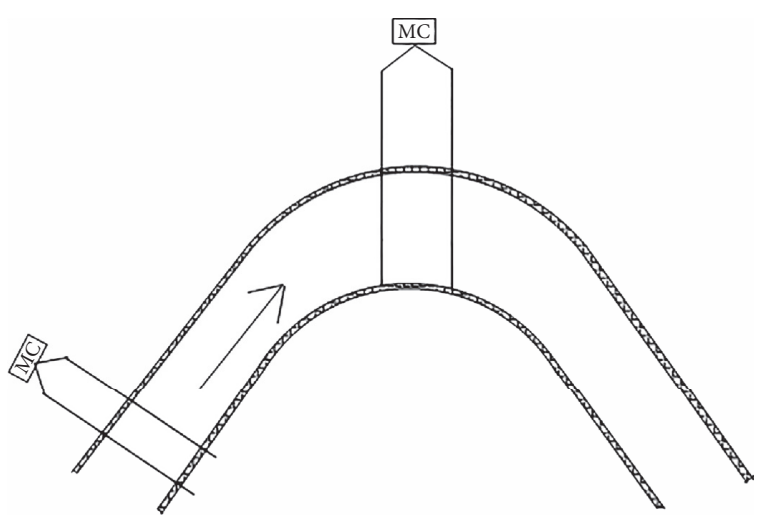

Figure 3: Typical Metrocount layout.

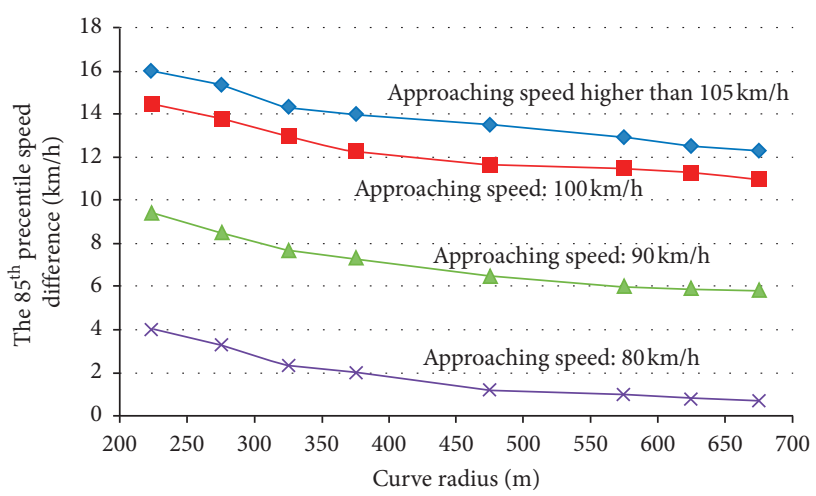

Figure 4: Relationship between various approach speed differences and curve radius.

If the operating speed of the passenger cars lay between $100 \mathrm{~km} / \mathrm{h}$ and $105 \mathrm{~km} / \mathrm{h}$, the speed difference would definitely exceed $10 \mathrm{~km} / \mathrm{h}$, which indicated that the speed limit should be updated. When limited curves radii of $250 \mathrm{~m}$ were adopted, the speed difference exceeded $15 \mathrm{~km} / \mathrm{h}$, necessitating a decrease in the operating speed to $85 \mathrm{~km} / \mathrm{h}$ on the curves.
TABLE 3: Speed difference estimation results.

\begin{tabular}{lcccc}
\hline Speed difference $(\mathrm{km} / \mathrm{h})$ & \multicolumn{4}{c}{$\begin{array}{c}\text { Passenger car approach speed } \\
\text { Horizontal curves radius }(\mathrm{m})\end{array}$} \\
& 80 & 90 & 100 & 105 \\
\hline 250 & 5.07 & 10.27 & 15.48 & 17.02 \\
300 & 4.16 & 9.36 & 14.56 & 16.11 \\
400 & 3.02 & 8.22 & 13.42 & 14.97 \\
500 & 2.33 & 7.53 & 12.74 & 14.28 \\
600 & 1.88 & 7.08 & 12.28 & 13.83 \\
700 & 1.55 & 6.75 & 11.96 & 13.50 \\
\hline
\end{tabular}

If the operating speed of passenger cars was above $105 \mathrm{~km} / \mathrm{h}$, the speed difference increased and exceeded $10 \mathrm{~km} / \mathrm{h}$. When the radius was smaller than $300 \mathrm{~m}$, the speed difference reached $15 \mathrm{~km} / \mathrm{h}$.

2.5. Advisory Speed Sign Setting. According to the methods proposed in the MUTCD for setting speed limits, the drivers will slow down to a certain speed regardless of the curve radius.

In this study, advisory speed signs were set on the basis of the speed differences of passenger cars. The maximum speed limit was $100 \mathrm{~km} / \mathrm{h}$ for mountainous freeways. Therefore, operating speed and safety characteristics information were combined to decide the value of the advisory speed sign:

$$
\text { AD_SL }=\min \left(V_{\text {design }}, V_{\text {operating }}\right) \text {, }
$$

where AD_SL is the advisory speed in $\mathrm{km} / \mathrm{h}, V_{\text {design }}$ is the design speed in $\mathrm{km} / \mathrm{h}$, and $V_{\text {operating }}$ is the operating speed in $\mathrm{km} / \mathrm{h}$.

In summation, an advisory speed sign was required only when the radius was smaller than $300 \mathrm{~m}$, a condition that would cause a speed difference larger than $15 \mathrm{~km} / \mathrm{h}$. The advisory speed sign setting is shown in Table 4 . 
TABLE 4: Advisory speed sign setting.

\begin{tabular}{lccccc}
\hline Curve radius $(\mathrm{m})$ & 250 & 300 & 400 & 500 & 600 \\
\hline Advisory speed limit $(\mathrm{km} / \mathrm{h})$ & 80 & 80 & 90 & 90 & 90 \\
\hline
\end{tabular}

\section{Results and Discussion}

3.1. Determination of Speed Difference. The reasonable speed difference can meet the driver's demand for speed and ensure driving safety. It can be seen from the results in Figure 4 and Table 2 that the approaching speed is positively correlated with the speed difference, while the curves radius is negatively correlated with the speed difference. This shows that the established linear regression model can accurately fit the actual situation.

Speed limit also has a great impact on road capacity and traffic safety. With the increase in the speed limit, the road capacity will increase, but it will also increase the possibility of accidents. Lowered speed limit reduces the risk from the accident and the externality cost like accident cost. Sugiyanto et al. conducted a study on the effect of speed limit signs, and the results showed that the installation of speed limit signs on the highway is less effective to reduce vehicle speed. After the speed limit sign is installed, the vehicle speed is reduced only about $2.9 \mathrm{~km} / \mathrm{h}$ to $5.5 \mathrm{~km} / \mathrm{h}$ (5.6 to $10.1 \%$ ) [37]. The speed limit studied in this paper is $80 \mathrm{~km} / \mathrm{h}$ and $120 \mathrm{~km} / \mathrm{h}$. Based on the above research, it can be seen that the driving speed of vehicles is relatively high when approaching the curve section, mainly in the range of $80 \mathrm{~km} /$ $\mathrm{h}$ to $105 \mathrm{~km} / \mathrm{h}$. Hence, it is suggested that the advisory speed should ensure the driver expectation and road safety.

3.2. Location of Advisory Speed Signs. Warning signs should be placed to allow adequate time for drivers to perceive, identify, and perform any necessary maneuver when approaching a curve. The locations for advisory speed signs should take driver minimum requirements and traffic investigation results into consideration. Advanced distance is an important parameter for the placement of advisory speed signs. The typical location at a curve is shown in Figure 5.

In order to determine the advance distance for the advisory speed sign location [38], the driver identification process was analyzed, as shown in Figure 6.

In Figure 6, it is assumed that the vehicle travels from East to West. An advisory speed sign is located at point $P$. A driver perceives the traffic sign at $A$. When the vehicle reaches point $B$, the driver starts to read the sign and completes this process at point $C$. The distance between $B$ and $C$ is termed the reading distance $b$. The driver then makes a decision based on their judgment. The vehicle travels from $C$ to $D$ during the response time. A driver takes relevant action at point $E$ and finishes at point $F$.

The distance between $A$ and $P$ is termed the visibility distance for the advisory speed sign. $K$ denotes the distance from $C$ to $P$. $x$ denotes the advance distance from $P$ to $F$. $m$, the distance from $D$ to $P$, is termed the minimum maneuver distance. The distance from $E$ to $F$ is termed the operating distance $L$. In order to ensure an adequate

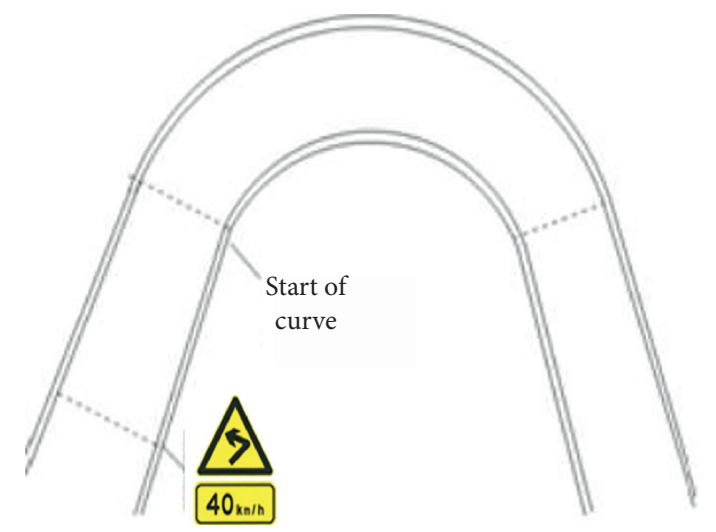

Figure 5: Advisory speed sign at the curve.

distance for the driver to understand the speed limit, the sum of the visibility distance and the advanced setting distance must be greater than the sum of the operating distance, the decision distance, the response distance, and the reading distance [39]:

$$
\begin{aligned}
S+x & \geq L+C+J+b, \\
x & \geq V_{1} t_{1}+V_{1} t_{2}+V_{1} t_{3}+L-S,
\end{aligned}
$$

where $J$ is the travel distance during the response time; $C$ is the decision distance; $b$ is the reading distance; $L$ is the operating distance; $V_{1}$ is the vehicle operating speed at points $B, C$, and $D$ in $\mathrm{km} / \mathrm{h} ; t_{1}$ is the traffic sign reading time $\left(t_{1}=1.5 \mathrm{~s}\right) ; t_{2}$ is the determination time $\left(t_{2}=2 \mathrm{~s}\right)$; and $t_{3}$ is the response time $\left(t_{3}=1.5 \mathrm{~s}\right)$.

The maneuver distance $L$ can be calculated as follows:

$$
\begin{aligned}
& L=(n-1) L^{*}+\frac{\left(V_{1}^{2}-V_{2}^{2}\right)}{2 a}, \\
& L=(n-1) V_{1} t_{2}+\frac{\left(V_{1}^{2}-V_{2}^{2}\right)}{2 a},
\end{aligned}
$$

where $n$ is the number of lanes, $L^{*}$ is the lane change once required distance, $v_{1}$ is the speed of passenger vehicles at point $D, v_{2}$ is the speed of passenger vehicles at point $F$, and $a$ is the deceleration rate $\left(1 \mathrm{~m} / \mathrm{s}^{2}\right)$.

Based on the relevant Chinese standard [40], the maximum design speed for freeways is $120 \mathrm{~km} / \mathrm{h}$ and the minimum design speed is $80 \mathrm{~km} / \mathrm{h}$. Hence, $V_{1}$ is $120 \mathrm{~km} / \mathrm{h}$ and $V_{2}$ is $80 \mathrm{~km} / \mathrm{h}$. The maneuver distance $L$ is calculated as shown in Table 5.

If the operating speed is $120 \mathrm{~km} / \mathrm{h}$,

$$
V_{1} t_{1}+V_{1} t_{2}+V_{1} t_{3}=120 * \frac{(1.5+2+1.5)}{3.6}=166.7 .
$$

If the operating speed is $100 \mathrm{~km} / \mathrm{h}$,

$$
V_{1} t_{1}+V_{1} t_{2}+V_{1} t_{3}=100 * \frac{(1.5+2+1.5)}{3.6}=138 .
$$

If the operating speed is $80 \mathrm{~km} / \mathrm{h}$,

$$
V_{1} t_{1}+V_{1} t_{2}+V_{1} t_{3}=80 *(1.5+2+1.5)=111.1 \text {. }
$$



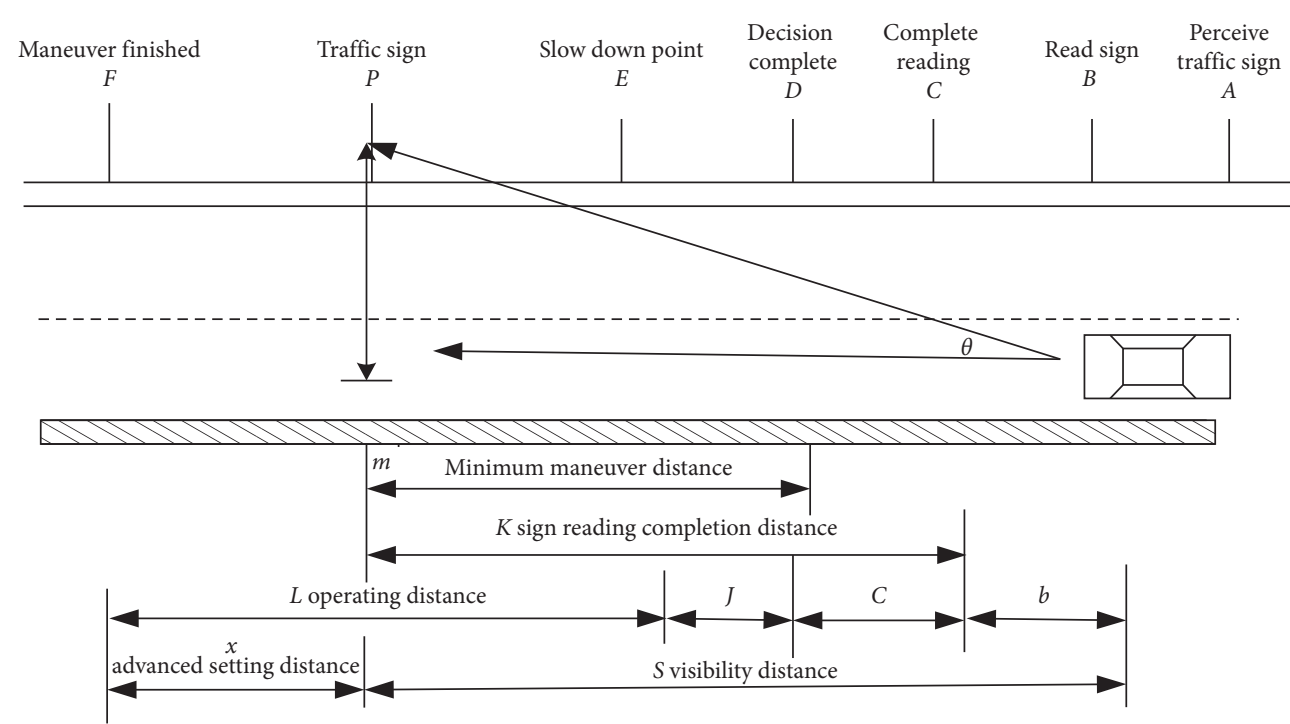

Figure 6: Driver traffic sign identification process.

TABle 5: Advisory speed sign for $L$.

\begin{tabular}{lcc}
\hline$V_{1}(\mathrm{~km} / \mathrm{h})$ & $V_{2}(\mathrm{~km} / \mathrm{h})$ & $L(\mathrm{~m})$ \\
\hline 120 & 60 & 483 \\
100 & 60 & 302 \\
80 & 60 & 152 \\
\hline
\end{tabular}

TABLE 6: Advanced setting distances for advisory speed signs.

\begin{tabular}{ccccc}
\hline$n$ & $V_{1}(\mathrm{~km} / \mathrm{h})$ & $L(\mathrm{~m})$ & $V_{1} t_{1}+V_{1} t_{2}+V_{1} t_{3}(\mathrm{~km} / \mathrm{h})$ & $x(\mathrm{~m})$ \\
\hline 2 & 120 & 483 & 166.7 & 600 \\
2 & 100 & 302 & 138 & 391 \\
2 & 80 & 152 & 111 & 214 \\
\hline
\end{tabular}

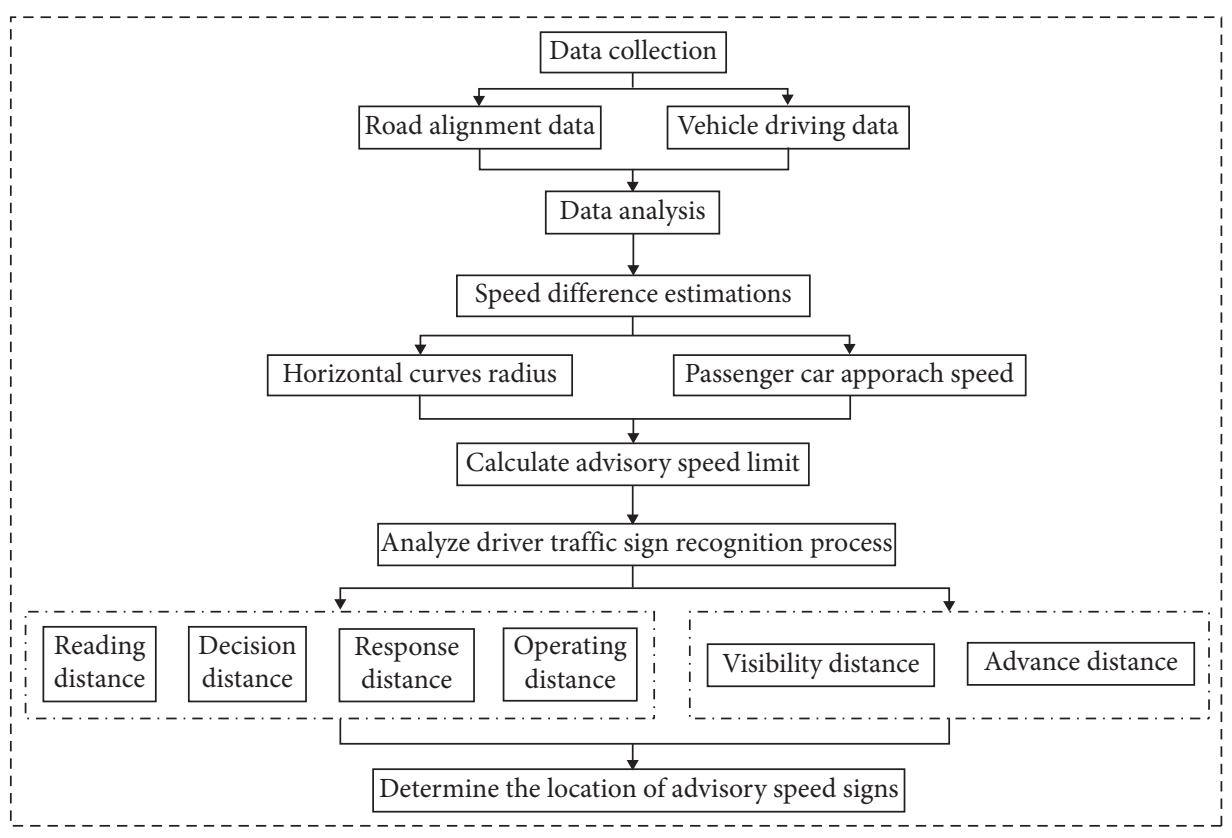

FIgURE 7: The model of determining speed difference and identifying the location of advisory speed signs. 
As for roadside advisory speed signs, $\theta$ is the degree between the straight line and the horizontal line which connect the driver's eyes and the upper edge of the traffic sign, $\theta$ is $7 \sim 10^{\circ}$ :

$$
S=\frac{d}{\tan \theta}=\frac{7}{\tan 8}=7 \frac{\cos 8}{\sin 8}=49.8,
$$

where $d$ is the vertical distance between the driver's eye and the roadside traffic sign, or the vertical distance between the driver's eye and the upper edge of the traffic sign.

The advanced setting distance for advisory speed signs was calculated based on different operating speeds and the number of lanes as shown in Table 6.

It can be seen from Table 6 that the approach speed has a great influence on the advanced setting distance. When the approach speed is $80 \mathrm{~km} / \mathrm{h}$, the advanced setting distance of $214 \mathrm{~m}$ can meet the requirements; when the speed is increased to $120 \mathrm{~km} / \mathrm{h}$, the advanced setting distance of $600 \mathrm{~m}$ is required to ensure traffic safety.

The model for determining the speed difference and identifying the location of advisory speed signs is shown in Figure 7.

This article mainly studies the determination of the speed difference of different curve sections and the setting of identification marks, but the paper still has content that can be further studied. The main research object of this article is the passenger car. In the future research, the car models can be divided into three types: small car, medium car, and large car. On this basis, more detailed research will be conducted on each model. At the same time, other models can be used to estimate the speed difference, so that more accurate results can be obtained. Besides, the process of driver identification can be combined with the driver characteristics and other factors for more accurate analysis and research.

\section{Conclusions}

This study aimed to develop guidelines for advisory speed sign placement. Operating speeds were collected at the approach and middle of curves located on mountainous freeways in eight provinces. The following conclusions were drawn.

(1) The speed difference is inversely proportional to the curve radius and proportional to the approach speed.

(2) A linear model was developed to estimate passenger speed differences. An advisory speed sign was required when the speed difference was larger than $15 \mathrm{~km} / \mathrm{h}$.

(3) The results of the linear regression model show that the approach speed and the curve radius have a great influence on the speed difference. When the approach speed exceeds $100 \mathrm{~km} / \mathrm{h}$, the speed difference will exceed $10 \mathrm{~km} / \mathrm{h}$.

(4) Based on the analysis of the data of the survey section, the corresponding advisory speed limit under different curve radius is obtained. When the radius of the curve is between $250 \mathrm{~m}$ and $300 \mathrm{~m}$, the advisory speed limit of this curve section is $80 \mathrm{~km} / \mathrm{h}$; when the radius of the curve is greater than $400 \mathrm{~m}$, the advisory speed limit is $90 \mathrm{~km} / \mathrm{h}$.

(5) The determination of the location of advisory speed signs should consider the whole process from the discovery of the sign to the end of the corresponding measures taken by the driver.

(6) The location of advisory speed signs was calculated taking traffic safety and driver visual range into consideration based on the operating speed.

(7) An advisory speed sign was required when the design speed was $80 \mathrm{~km} / \mathrm{h}$ and the radius of the curve was smaller than $300 \mathrm{~m}$.

(8) The approach speed has a great influence on the advanced setting distance. As the approach speed increases, the required advanced setting distance will increase rapidly. When the approach speed is $80 \mathrm{~km} /$ $\mathrm{h}$, the advanced setting distance of $214 \mathrm{~m}$ can meet the requirements; when the approach speed is increased to $120 \mathrm{~km} / \mathrm{h}$, the advanced setting distance of $600 \mathrm{~m}$ is needed to ensure traffic safety.

\section{Data Availability}

The data used to support the findings of this study are available from the corresponding author upon request.

\section{Conflicts of Interest}

The authors declare that there are no conflicts of interest regarding the publication of this paper.

\section{Acknowledgments}

The authors thank Chang'an University for providing simulators and equipment. Also, special thanks are due to the graduate students who helped the authors in data collection. The research was supported by the National Science of Foundation of China (Grant no. U1664264, 51878066). The Project was supported by the Humanities and Social Sciences Youth Fund of Ministry of Education (18YJCZH110) and Fundamental Research Funds for the Central Universities in China (300102220111, 300102229668, 300102229201, 300102120111, and 300102220204).

\section{References}

[1] Traffic Management Bureau of the Ministry of Public Security, Statistical Report on Road Traffic Accident of China, Traffic Management Bureau of the Ministry of Public Security, Beijing, China, 2018.

[2] H. Huang, Y. Peng, J. Wang, Q. Luo, and X. Li, "Interactive risk analysis on crash injury severity at a mountainous freeway with tunnel groups in China," Accident Analysis \& Prevention, vol. 111, no. 2, pp. 56-62, 2018.

[3] M. Li, Y. G. Wang, W. Zhang et al., "Identifying significant factors influencing occurrence of fatal crash on mountainous freeway," China Safety Science Journal, vol. 25, no. 5, pp. 126-130, 2015. 
[4] Y. W. Meng, "Estimation of crash severity on mountainous freeways in Chongqing," Mathematical Problems in Engineering, vol. 2017, no. 2, Article ID 9764309, 2017.

[5] X. M. Wang, R. J. Yu, and X. S. Wang, "A speed study of mountainous freeway combined alignment," in Proceedings of the COTA International Conference of Transportation Professionals, pp. 2257-2265, Changsha, China, July 2014.

[6] X. Wang, X. Wang, B. Cai, and J. Liu, "Combined alignment effects on deceleration and acceleration: a driving simulator study," Transportation Research Part C: Emerging Technologies, vol. 104, no. 7, pp. 172-183, 2019.

[7] X. Wang and X. Wang, "Speed change behavior on combined horizontal and vertical curves: driving simulator-based analysis," Accident Analysis \& Prevention, vol. 119, no. 10, pp. 215-224, 2018.

[8] C. L. Wang, Y. Q. Hu, and P. Li, "Based on TruckSim safe speed under the influence of loading condition of corner threshold," Journal of Beijing University of Aeronautics and Astronautics, vol. 44, no. 6, pp. 1337-1346, 2018.

[9] K. Fitzpatrick, P. Carlson, M. Brewer et al., NCHRP Report 504: Design Speed, Operating Speed, and Posted Speed Practices, Transportation Research Board, Washington, DC, USA, 2003.

[10] H. Zhang, X. L. Zhang, and N. C. Lv, "Reliability design of superelevation on expressway small radius horizontal curve," Journal of Wuhan University of Technology (Transportation Science \& Engineering), vol. 43, no. 3, pp. 452-456, 2019.

[11] L. Yue, Y. C. Du, and H. Y. Yao, "Optimization of the minimum radius index of mountain road curve based on driving stability," Journal of Transportation Systems Engineering and Information Technology, vol. 18, no. 5, pp. 208-214, 2018.

[12] Q. M. Guo, X. S. Wang, and Z. G. Chen, "Modeling operation speed on mountainous freeways: a driving simulator study," Journal of Tongji University Natural Science, vol. 47, no. 7, pp. 1004-1010, 2019.

[13] M. Chowdhury, W. Davey, and H. Bissell, "Analysis of advisory speed setting criteria," Public Roads, vol. 55, no. 3, pp. 65-71, 1991.

[14] Y. M. Shao, J. C. Mao, and S. C. Liu, "Analysis of speed control behavior for driver on mountain highway," Journal of Traffic and Transportation Engineering, vol. 11, no. 1, pp. 79-88, 2011.

[15] S. E. Zhao, X. Qu, and J. L. Zhang, "Prediction of safe vehicle speed on curved roads based on driver-vehicle-road collaboration," Automotive Engineering, vol. 37, no. 10, pp. 12081214, 2015.

[16] C. Sun, Z. C. Wu, and R. F. Chun, "Improved model study of safety speed calculation in curves," China Journal of Highway and Transport, vol. 28, no. 2, pp. 101-108, 2015.

[17] T. Chen, M. Zhang, and L. Wei, "Driver behavior on combination of vertical and horizontal curves of mountainous freeways," Mathematical Problems in Engineering, vol. 2014, no. 4, Article ID 432841, 2014.

[18] J. Xu, Y. Shao, Q. Peng, and C. Jiang, "Steering task complexity analysis on highway alignment and design control," Journal of Southeast University (Natural Science Edition), vol. 39, no. 4, pp. 867-872, 2009.

[19] Y. Wu, Y. Lu, and F. Li, "Research on safety and speed-limit of oversize vehicle on expressway curve sections," Highway, vol. 60, no. 4, pp. 162-168, 2015.

[20] J. Xu, J. Zhou, X. Wang, and Y.-M. Shao, "Longitudinal acceleration performance of passenger cars on complex mountain highways," China Journal of Highway and Transport, vol. 30, no. 4, pp. 115-126, 2017.
[21] T. Chen, Z. Yang, X. Li, and L. Wei, "Speed prediction of the combination of horizontal and vertical alignments based on driver's preview and BP neural network," ICIC Express Letters, vol. 9, no. 3, pp. 921-927, 2015.

[22] Y. S. Guo, R. Fu, W. Yuan, and Y.-L. Li, "Relation between accident rate and horizontal alignment for mountain highway," Journal of Traffic and Transportation Engineering, vol. 12, no. 1, pp. 63-71, 2012.

[23] H. Wang, J. L. Xu, X. L. Jia et al., "Sideslip simulation and safe driving speed of truck on highway curve section," Journal of Chang'an University: Natural Science Edition, vol. 37, no. 6, pp. 31-37, 2017.

[24] J. L. He, B. Gong, T. Zhu et al., "Critical safety speed model of corners based on road geometry parameters," Journal of Changsha University of Science and Technology: Natural Science, vol. 14, no. 4, pp. 75-82, 2017.

[25] Y. H. Yang, C. H. Wu, T. Ge et al., "Safety of stop sight distance of freeway passing lane for passenger car in mountainous area," Journal of Chang'an University. Natural Science Edition, vol. 34, no. 5, pp. 42-48, 2014.

[26] D. Wang, "Driving behavior test study of mountainous freeway straight and curve section," Journal of Changsha University of Science \& Technology, vol. 10, no. 4, pp. 36-40, 2013.

[27] L. Zheng, J. W. Sun, and X. H. Meng, "Crash prediction model for basic freeway segments incorporating influence of road geometrics and traffic signs," Journal of Transportation Engineering, Part A: Systems, vol. 144, no. 7, Article ID 04018030, 2018.

[28] M. J. Feng, T. G. Wang, X. S. Wang, and Y. Deng, "Safety evaluation of combined horizontal and vertical alignments on mountainous freeways," Journal of Beijing University of Technology, vol. 6, no. 9, pp. 19-25, 2018.

[29] ASCE, Manual on Uniform Traffic Control Devices, Australian Standard, Sydney, Australia, 2010.

[30] T. R. Neuman, P. Ronald, and K. L. Slak, Guidance for Implementation of the AASHTO Strategic Highway Safety Plan: Safety Data and Analysis in Developing Emphasis Area Plans, Vol. 21, Transportation Research Board, Washington, DC, USA, 2008.

[31] A Policy on Geometric Design of Highways and Streets, American Association of State Highway and Transportation Officials, Washington, DC, USA, 5th edition, 2004.

[32] S. P. Venglar, Establishing Advisory Speeds on Freeway Exit Ramps, Transportation Research Board, Washington, DC, USA, 2010.

[33] W. W. Zhou, Roadway Traffic Sign and Marking Setting Manual, Water Resources and Hydropower Press, Beijing, China, 2007.

[34] JTG D82-2009, Specification for Layout of Highway Traffic Signs and Markings, Ministry of Transport of the People's Republic of China, Research Institute of Highway Ministry of Transport, Beijing, China, 2009.

[35] X. D. Sun, Y. S. Chen, and Y. L. He, Chinese Highway Accidents Characteristics and Safety Improvement from Jingjing Tang Freeway as a Case, International Highway Safety Meeting: Beijing: People and Traffic Press, Chongqing, China, 2004.

[36] J. Bonneson, M. Pratt, J. Miles et al., Development of Guidelines for Establishing Effective Curve Advisory Speeds, Texas Transportation Institute, College Station, TX, USA, 2007. 
[37] G. Sugiyanto and S. Malkhamah, "Determining the maximum speed limit in urban road to increase traffic safety," Jurnal Teknologi, vol. 80, no. 5, pp. 67-77, 2018.

[38] J. J. Wang, H. B. Zhong, and X. F. Zhao, Road Traffic Sign Design Theory and Method, Science Press, Beijing, China, 2008.

[39] M. A. Chowdhury, D. L. Warren, and H. Bissell, "Analysis of advisory speed setting criteria," Public Roads, vol. 55, no. 3, pp. 23-26, 1991.

[40] JTG D20-2017, Design Specification for Highway Alignment, Ministry of Transport of the People's Republic of China, CCCC First Highway Consultants Co., Ltd, Beijing, China, 2017. 